Hydrol. Earth Syst. Sci., 17, 4471-4480, 2013

www.hydrol-earth-syst-sci.net/17/4471/2013/

doi:10.5194/hess-17-4471-2013

(c) Author(s) 2013. CC Attribution 3.0 License.

\title{
Responses of natural runoff to recent climatic variations in the Yellow River basin, China
}

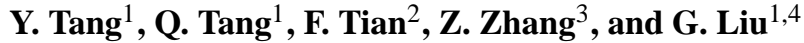 \\ ${ }^{1}$ Institute of Geographic Sciences and Natural Resources Research, Chinese Academy of Sciences, Beijing 100101, China \\ ${ }^{2}$ State Key Laboratory of Hydroscience and Engineering \& Department of Hydraulic Engineering, Tsinghua University, \\ Beijing 100084, China \\ ${ }^{3}$ College of Soil and Water Conservation, Beijing Forestry University, Beijing 100083, China \\ ${ }^{4}$ University of Chinese Academy of Sciences, Beijing 100049, China
}

Correspondence to: Q. Tang (tangqh@igsnrr.ac.cn)

Received: 5 March 2013 - Published in Hydrol. Earth Syst. Sci. Discuss.: 8 April 2013

Revised: 13 October 2013 - Accepted: 16 October 2013 - Published: 12 November 2013

\begin{abstract}
The zero-flow phenomenon appeared frequently in the lower reaches of the Yellow River in China in the 1990s, whereas it has almost disappeared in recent years. The disappearance of the zero-flow phenomenon should be mainly attributed to the recent water management practices. However, little is known about the effects of recent climatic variations on natural runoff. In this study, we investigated the impacts of climatic variations on natural runoff above the Huayuankou station. The results indicate that there was little increase in precipitation, but substantial recovery of natural runoff in the recent period (2003-2011) compared with the low-flow period (1991-2002). The recent precipitation was slightly greater $(\sim 2 \%$ of the baseline precipitation in 1960 1990) than precipitation in the low-flow period. However, the recent natural runoff was much larger $(\sim 14 \%$ baseline runoff) than runoff in the low-flow period. The runoff reduction in the low-flow period was mainly caused by precipitation decrease. In the recent period, precipitation accounted for a runoff reduction ( $\sim 21 \%$ baseline runoff), whereas net radiation, wind speed, air temperature, and relative humidity accounted for a runoff increase ( $\sim 7.5 \%$ baseline runoff). The spatial pattern of the climatic variation is a factor influencing the response of runoff to climatic variations. The reduction in runoff induced by precipitation change was offset up to half by the impacts of changes in net radiation and wind speed at most sub-basins in the recent period.
\end{abstract}

\section{Introduction}

The Yellow River, the cradle of Chinese civilization, is a major source of freshwater for about 107 million people within the river basin, about $9 \%$ of the total population in China (Wang et al., 2006). The upper and middle reaches of the river are located in semi-arid and semi-humid areas (Tang et al., 2008a). The Yellow River basin is one of the regions facing serious water shortages due to the dry climate and heavy water demands (Yang et al., 2004). After the completion of a few irrigation projects in the 1960s, the lower reaches have increasingly suffered from extreme low-flow conditions (Tang et al., 2008b). The Yellow River zero-flow phenomenon, i.e., zero flow in the lower reaches of the mainstream, has occurred since 1972 (Yang et al., 2004). The frequency of the zero-flow phenomenon increased rapidly in the 1990s. However, it seemed to disappear in the 2000s (Zhang et al., 2009). Numerous studies have investigated the hydrological change in the Yellow River basin and tried to explain the zero-flow phenomenon (Yang et al., 2004; Liu and Zheng, 2004; Fu et al., 2004; Xu, 2005; Tang et al., 2006, 2007). The frequent zero-flow phenomenon in the 1990s was attributed to intensified human activities and climatic changes. As for the Huayuankou station, a hydrological gauge that controls most (approximately $97 \%$ of the total) areas of the Yellow River basin, natural runoff had a significant decreasing trend during the period of 1952-1997 (Liu and Zheng, 2004). Climatic change is a dominant cause of the reduction in river flow above the Huayuankou station (Cong et al., 2009), 
accounting for about three quarters of annual streamflow changes (Tang et al., 2008b). In contrast to the extensive studies on the causes of the zero-flow phenomenon, possible reasons for the disappearing zero-flow phenomenon in recent years (Zhang et al., 2009) have been less studied. With recognition of trade-off between human and eco-environmental water use and allocations of more water to maintain the ecological environment, water management practices such as reservoir regulation should have helped to prevent the zeroflow phenomenon (Yang et al., 2008; Hu et al., 2008; Cui et al., 2009). Meanwhile, recent climatic variation in the river basin, which has a large impact on river flow, may have also contributed to the river replenishment.

Previous studies showed that the hydroclimatic changes in the Yellow River basin varied spatially. According to the river discharge records and the China Meteorological Administration (CMA) weather observations, precipitation in the source region of the Yellow River was low in the 1990s, but returned to above normal after 2002, while discharge remained low (Zhou and Huang, 2012). In the Hailiutu river basin, a small catchment $\left(\sim 2600 \mathrm{~km}^{2}\right)$ in the middle reaches of the Yellow River, the river discharge reached its lowest level in the 1990s and recovered in the 2000s (Yang et al., 2012). At the river mouth, annual streamflow decreased severely from 1997 to 2002, but increased thereafter as the direct beneficiary of the environment-friendly water resource allocation projects (Cui et al., 2009; Yu et al., 2011). Although reservoir regulations may help to increase the low flow in the river channel, there must be enough water in the river systems to enable the allocation for eco-environmental water use. It is unknown how the recent climatic variations may affect natural runoff and whether the change in natural runoff helps to avoid the zero-flow phenomenon. Understanding the changes in natural runoff is essential for explaining the observed streamflow change at the lower reaches in the recent decade and is informative for future water resource management in the Yellow River basin. Unless otherwise noted, runoff in this paper refers to the natural runoff that would have occurred prior to human influences. Since the catchment area between Huayuankou station and the river mouth is small (about $3 \%$ of the total catchment area), and the river flow between Huayuankou station and the river mouth is largely withdrawn for irrigation (Tang et al., 2008b), the runoff above the Huayuankou station is of special interest.

A hydrological model, the Soil and Water Assessment Tool (SWAT), was used to simulate the runoff in the catchment above the Huayuankou station. SWAT is a hydrological model developed to evaluate water resources in large agricultural basins (Arnold et al., 1998; Arnold and Fohrer, 2005). The SWAT model has been used to assess water resource and nonpoint pollution problems at a wide range of scales across the globe. It has also been used in many hydrological applications and climatic change studies in the Yellow River basin and its sub-basins ( $\mathrm{Li}$ et al., 2009; Xu et al., 2009; Liu et al., 2011; Xu et al., 2011). The climate elasticity of

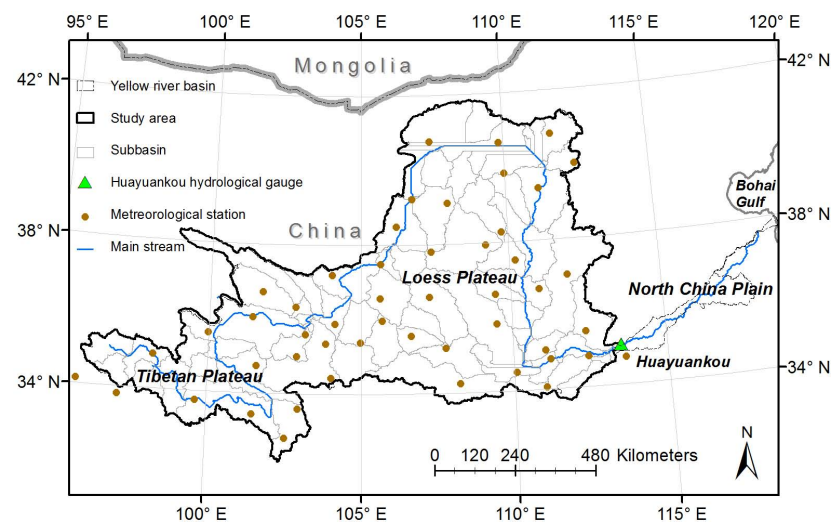

Fig. 1. The study area and sub-basins.

runoff derived by Yang and Yang (2011) was used to further attribute the runoff change to changes in different climatic variables. Climate elasticity of runoff was defined by the proportional change in runoff to the proportional change in a climatic variable such as precipitation (Schaake, 1990). Climate elasticity of runoff provides a measure of the sensitivity of runoff to the changes in the climatic variables (e.g., precipitation and temperature) and is widely used in the impact assessment of climatic changes on hydrology (Sankarasubramanian et al., 2001; Chiew, 2006; Fu et al., 2007; Zheng et al., 2009; Tang and Lettenmaier, 2012). The streamflow sensitivities to the changes in the climatic variables have been analytically explored in some previous studies (Liu and Cui, 2011; Liu and McVicar, 2012). This paper compared the analytical estimates with the runoff simulations from SWAT model, and investigated the possible climatic contributions to the recent runoff change at the Huayuankou station and at the sub-basins. The paper concluded with the changes in recent runoff and the contributions of the changes in different climatic variables to the runoff changes.

\section{Study area and data}

The Yellow River originates in the Tibetan Plateau, flows through the Loess Plateau and North China Plain, and discharges into the Bohai Gulf (Fig. 1). The study area is the catchment above the Huayuankou station with a drainage area of $730000 \mathrm{~km}^{2}(\sim 97 \%$ of the total area of the Yellow River basin). The mean annual runoff in the study area accounts for $\sim 98 \%$ of that in the whole Yellow River basin (Liu et al., 2011). The study area is largely in the semi-arid to semi-humid regions where the mean annual precipitation ranges from 300 to $700 \mathrm{~mm}$.

Meteorological data from 50 weather stations inside and close to the study area were obtained from the China Meteorological Administration (CMA). The data set includes daily precipitation $(P)$, mean air temperature $(T)$, maximum temperature $\left(T_{\max }\right)$, minimum temperature $\left(T_{\min }\right)$, surface 
relative humidity $(\mathrm{RH})$, wind speed at $10 \mathrm{~m}$ height $\left(U_{10}\right)$, and sunshine duration $(n)$ from 1955 to 2011 . The monthly naturalized streamflow data from 1960 to 2000 were obtained from the Yellow River Conservancy Committee (YRCC), while the recent data (from 2001 to 2011) were unavailable. The naturalized streamflow is the streamflow record adjusted to remove the impacts of water management. The YRCC has developed a mature technology to reconstruct the naturalized streamflow of the Yellow River (Dong et al., 2001). The naturalized flow was directly comparable with the simulated natural streamflow. The digital elevation model (DEM) with a spatial resolution of $1 \mathrm{~km} \times 1 \mathrm{~km}$ was generated from the International Center for Tropical Agriculture (CIAT) product (Reuter et al., 2007) archived at the Computer Network Information Center, Chinese Academy of Sciences (http://datamirror.csdb.cn). The land cover/use map of the 1980s was taken from the Institute of Geographical Sciences and Natural Resources Research (IGSNRR), Chinese Academy of Sciences (CAS) (Liu et al., 2002). The fixed land cover map was used throughout the study period. The land surface vegetation change may affect the surface water and energy partitioning (Zhang et al., 2012), and influence the hydrological cycle (Tang et al., 2008a, 2012). The previous studies suggested that comparing climatic changes with land cover change might be a less significant factor in runoff change above the Huayuankou station in the Yellow River basin (Tang et al., 2008a; Cong et al., 2009). There are complicated interactions among land cover change, human activities, regional climate, and hydrological cycles. The impact of land use change, a large part of which may be attributed to human influences, is out of the scope of this study, which focuses on natural runoff responses to climatic variations. The soil parameters were estimated by the Soil Water Characteristics application of the Soil-Plant-Air-Water (SPAW) model (Saxton and Rawls, 2006), based on the soil texture and organic matter data provided in the China Soil Scientific Database (http://www.soil.csdb.cn).

\section{Method}

The potential evaporation $\left(E_{0}\right)$ was estimated using the Penman equation (Penman, 1948):

$$
\begin{aligned}
E_{0} & \frac{\Delta}{\Delta+\gamma}\left(R_{\mathrm{n}}-G\right) / \lambda+\frac{\gamma}{\Delta+\gamma} 6.43\left(1+0.536 U_{2}\right) \\
& (1-\mathrm{RH}) e_{\mathrm{s}} / \lambda
\end{aligned}
$$

where $\Delta$ is the slope of the saturated vapor pressure versus air temperature curve $\left(\mathrm{kPa}^{\circ} \mathrm{C}^{-1}\right), \gamma$ is the psychrometric constant $\left(\mathrm{kPa}{ }^{\circ} \mathrm{C}^{-1}\right), \lambda$ is the latent heat of vaporization $\left(2.45 \mathrm{MJ} \mathrm{kg}^{-1}\right), R_{\mathrm{n}}$ and $G$ are the net radiation and soil heat flux $\left(\mathrm{MJ} \mathrm{m}^{-2} \mathrm{~d}^{-1}\right)$, respectively, $e_{\mathrm{s}}$ is the saturated vapor pressure ( $\mathrm{kPa}), \mathrm{RH}$ is the relative humidity (\%), and $U_{2}$ is the wind speed at a height of $2 \mathrm{~m}\left(\mathrm{~m} \mathrm{~s}^{-1}\right)$. The observed wind speed at $10 \mathrm{~m}$ height was adjusted to the standard height of $2 \mathrm{~m}\left(U_{2}, \mathrm{~m} \mathrm{~s}^{-1}\right)$ (Allen et al., 1998):

$U_{2}=U_{z} \frac{4.87}{\ln (67.8 z-5.42)}=0.75 U_{10}$,

where $U_{z}$ measured wind speed at $z$ meters above ground surface $\left(\mathrm{m} \mathrm{s}^{-1}\right) ; z$ is the height of measurement above ground surface (m). The daily net radiation $R_{\mathrm{n}}\left(\mathrm{MJ} \mathrm{m}^{-2}\right.$ day $\left.^{-1}\right)$ was estimated as:

$$
\begin{aligned}
& R_{\mathrm{n}}=(1-\alpha) R_{\mathrm{S}}-\sigma\left[\frac{\left(T_{\max }=273.2\right)^{4}+\left(T_{\min }+273.2\right)^{4}}{2}\right] \\
& \left(0.1+0.9 \frac{n}{N}\right) \times\left(0.34-0.14 \sqrt{\frac{\mathrm{RH}}{100} e_{\mathrm{S}}}\right),
\end{aligned}
$$

where $\alpha$ is albedo or the canopy reflection coefficient (dimensionless), $R_{\mathrm{S}}$ is solar or shortwave radiation $\left(\mathrm{MJ} \mathrm{m}^{-2} \mathrm{day}^{-1}\right), \sigma$ is the Stefan-Boltzmann constant $\left(4.903 \times 10^{-9} \mathrm{MJ} \mathrm{K}^{-4} \mathrm{~m}^{-2} \mathrm{day}^{-1}\right), T_{\max }$ is daily maximum air temperature $\left({ }^{\circ} \mathrm{C}\right), T_{\min }$ is daily minimum air temperature $\left({ }^{\circ} \mathrm{C}\right), n$ is daily actual sunshine duration $(h), N$ is daily maximum possible duration of sunshine $(h)$, and RH is daily relative humidity $(\%)$. Albedo $(\alpha)$ was set here as 0.23 for the hypothetical grass reference crop. $R_{\mathrm{S}}$ is calculated using the Angström formula relating solar radiation to extraterrestrial radiation and relative sunshine duration (Angström, 1924). $e_{\mathrm{s}}$ is estimated as:

$$
\begin{aligned}
e_{\mathrm{S}} & =0.3054\left[\exp \left(\frac{17.27 T_{\max }}{T_{\max }+237.3}\right)\right. \\
& \left.+\exp \left(\frac{17.27 T_{\min }}{T_{\min }+237.3}\right)\right]
\end{aligned}
$$

The linear trends of the mean annual basin-averaged climatic variables were calculated. The statistical significance of the annual trend was tested by the two-tailed Student's $t$ test. We divided the time series into three periods, i.e., the base flow (1960-1990), low-flow (1991-2002), and recent (20032011) periods, according to the frequency of the zero-flow phenomenon in the lower reaches of the Yellow River. The mean annual value during the historical period of 1960-1990 was used as the baseline. The period of 1991-2002 was the low-flow period when the frequency of the zero-flow phenomenon peaked (Cui et al., 2009; Yu et al., 2011; Zhou and Huang, 2012). We are particularly interested in the recent period (2003-2011) when the frequency of the zero-flow phenomenon went down to zero (Yang et al., 2008; Hu et al., 2008; Cui et al., 2009). The relative changes in the climatic and hydrological variables to the baseline were computed for the low-flow (1991-2002) and recent (2003-2011) periods, respectively.

The SWAT model was set up to simulate the runoff in the Yellow River basin. The catchment above the Huayuankou station was divided into 76 sub-basins, ranging from 32 to 
$40194 \mathrm{~km}^{2}$ (Fig. 1). The SWAT model ran at daily time step from 1955 to 2000. The first five years (1955-1959) served as a warm-up period to general initial conditions for the model experiments. The simulated runoff was manually calibrated against the monthly naturalized streamflow in the period of 1960-1979 and validated in the period of 1980-2000. The Relative Error $\left(E_{\mathrm{r}}\right)$, and Nash-Sutcliffe efficiency $\left(E_{\mathrm{NS}}\right)$ were used to evaluate the model performance:

$E_{\mathrm{r}}=\frac{S_{i}-O_{i}}{O_{i}} \times 100 \%$,

$E_{\mathrm{NS}}=1 \frac{\sum_{i=1}^{N}\left(O_{i}-S_{i}\right)^{2}}{\sum_{i=1}^{N}\left(O_{i}-\bar{O}\right)^{2}}$,

where $O_{i}$ is the observed naturalized streamflow, $S_{i}$ is the simulated runoff, $\bar{O}_{i}$ is the mean observed value, $\bar{S}_{i}$ is the mean simulated value, and $N$ is the total number of paired values, i.e., the number of years in the evaluated period. $E_{\mathrm{r}}$ gives the percent difference between the simulated and observed runoff over the evaluated period, and thus is of special interest in this study. An $E_{\mathrm{NS}}$ value of 1 is a perfect match of observed and simulated data. Generally model performance is very good if $E_{\mathrm{NS}}>0.75$, satisfactory if $0.36<E_{\mathrm{NS}}<0.75$, and unsatisfactory if $E_{\mathrm{NS}}<0.36$ (Nash and Sutcliffe, 1970; Krause et al., 2005; Moriasi et al., 2007). The validated model continued to simulate the natural streamflow into 2001-2011, when the observed streamflow data were missing.

The climate elasticity of runoff $(\varepsilon)$ was used to attribute the changes in runoff to changes in different climatic variables for the low-flow and recent periods. The runoff elasticities to precipitation $(P)$, net radiation $\left(R_{\mathrm{n}}\right)$, mean air temperature $(T)$, wind speed $\left(U_{2}\right)$, and relative humidity $(\mathrm{RH})$ were derived using the mean annual climatic variables in the baseline period following the derivation described in Yang and Yang (2011). Runoff $(R)$ change was expressed as:

$\frac{\mathrm{d} R}{\bar{R}}=\varepsilon_{p} \frac{\mathrm{d} P}{\bar{P}}+\varepsilon_{R_{n}} \frac{\mathrm{d} R_{n}}{\bar{R}_{n}}+\varepsilon_{T} \mathrm{~d} T+\varepsilon_{U_{2}} \frac{\mathrm{d} U_{2}}{\bar{U}_{2}}+\varepsilon_{\mathrm{RH}} \frac{\mathrm{dRH}}{\overline{\mathrm{RH}}}$,

where $\bar{R}, \bar{P}, \overline{U_{2}}, \overline{R_{\mathrm{n}}}$, and $\overline{\mathrm{RH}}$ are the mean annual values in the baseline period, $\varepsilon_{p}, \varepsilon_{R_{n}}, \varepsilon_{T}, \varepsilon_{U_{2}}$, and $\varepsilon_{\mathrm{RH}}$ are the runoff elasticities. The runoff elasticity to temperature $\left(\varepsilon_{T}\right)$ implies that $1{ }^{\circ} \mathrm{C}$ increase in $T$ could lead to $\%$ change in runoff, and the elasticity to the other climatic variables (i.e., $P, R_{\mathrm{n}}$, $U_{2}$, and RH) implies that $1 \%$ change in each climatic variable could induce $\varepsilon \%$ change in runoff. Once the runoff elasticities were estimated, relative runoff changes in the lowflow and recent periods to the baseline period could be derived from the changes of climatic variables according to Eq. (7). The derived runoff changes were compared with the
SWAT model estimates and the naturalized streamflow at the Huayuankou station. The climate elasticities of runoff were calculated at each sub-basin and also at the Huayuankou station using the SWAT-simulated runoff.

\section{Results}

Figure 2 shows the variations in the climatic variables and potential evaporation over the study area during the period of 1960-2011. There is a significant increase trend $(p<0.001)$ in $T$ and significant decrease trends in $U_{2}, R_{\mathrm{n}}$ and RH. The warming trend of the Yellow River basin has been reported in previous studies (Fu et al., 2004; Tang et al., 2008a) and is consistent with the general increase in surface air temperature over global land surface (Hansen et al., 2006). The decline in wind speed has been documented over China (Jiang et al., 2010; Fu et al., 2011; Lin et al., 2013) and seems to be a part of widespread terrestrial stilling across the globe (McVicar et al., 2012). The decreasing trend of $R_{\mathrm{n}}$ is consistent with the reported declines in solar radiation across China (Tang et al., 2011) and in $R_{\mathrm{n}}$ in the adjacent Yangtze River basin (Xu et al., 2006). The decreasing RH is in line with previous studies, which reported a large decrease in relative humidity in many parts of China (Wang et al., 2012; Liu et al., 2010; Song et al., 2012). $P$ showed a decrease trend although the trend was not statistically significant during the period of 1960-2011 (Fu et al., 2004). A decreasing trend of $E_{0}$ is consistent with that in many previous studies (Ma et al., 2012; Liu and McVicar, 2012).

Mean annual precipitation in the low-flow period (19912002) was $47 \mathrm{~mm}(10.5 \%)$ less than that in the baseline period (1960-1990) (Table 1). The precipitation in the recent period (2003-2011) remained low-level, although it was larger ( $\sim 2 \%$ of the baseline precipitation in 1960-1990) than precipitation in the low-flow period. The precipitation in the recent period was $36 \mathrm{~mm}(8.1 \%)$ below the baseline. The temperatures in both the low-flow and the recent periods were higher than those in the baseline period, while there was little temperature difference between the low-flow and recent periods. The relative humidity in the recent period dropped about $9 \%$ from the baseline (Table 1). In the recent period, net radiation was about $10 \%$ below that in the baseline period and $2 \mathrm{~m}$ wind speed decreased about $18 \%$ from the baseline wind speed. Furthermore, the net radiation and wind speed in the recent period were the lowest among the three periods. Overall, the potential evaporation in the low-flow period is about the same as that in the baseline period, while the potential evaporation in the recent period was $5.3 \%$ lower than that in the baseline period (Table 1). The potential evaporation reflects the energy condition that affects the partition of precipitation into runoff and actual evaporation (Budyko, 1974; Roderick and Farquhar, 2011; Liu and McVicar, 2012). The reduction in potential evaporation might have affected runoff in the recent period. 

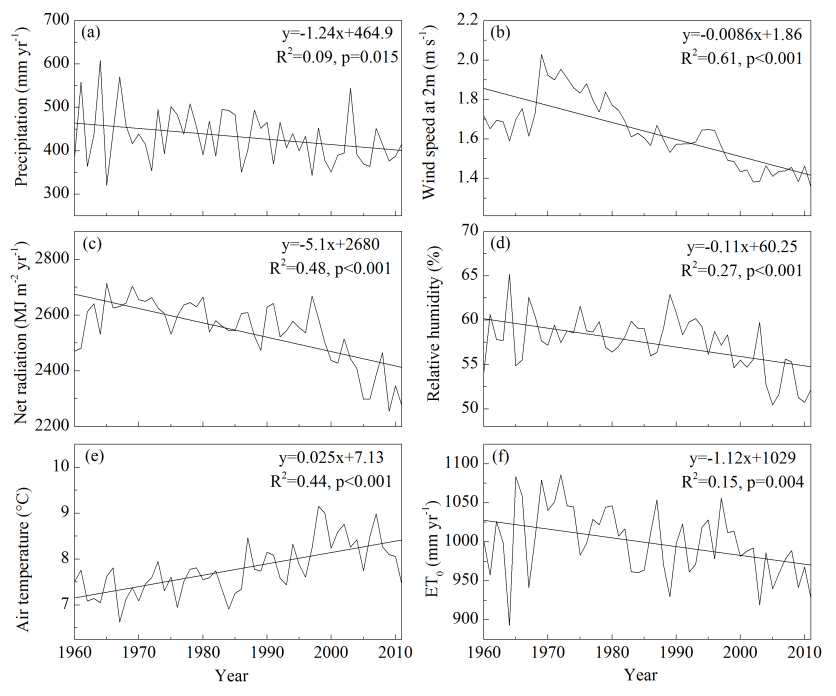

Fig. 2. Inter-annual variations in precipitation (a), wind speed at $2 \mathrm{~m}$ above the ground (b), net radiation (c), relative humidity (d), air temperature (e), and potential evapotranspiration (f) over the study area from 1960 to 2011.

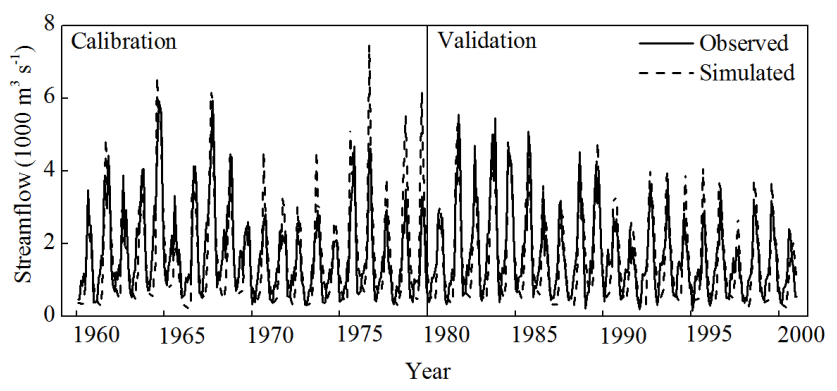

Fig. 3. Monthly comparisons between the SWAT-simulated streamflow and observed naturalized streamflow in the calibration (19601979) and validation (1980-2000) periods at the Huayuankou station. The vertical line divides the calibration and validation periods.

Figure 3 shows the monthly comparisons between the SWAT-simulated streamflow and observed naturalized streamflow in the calibration (1960-1979) and validation (1980-2000) periods at the Huayuankou station. Table 2 gives the evaluation scores of the SWAT performance in the calibration and validation periods. The SWAT-simulated streamflow agrees favorably with the observed naturalized streamflow. The $E_{\mathrm{NS}}$ is greater than 0.5 in both the calibration and validation periods, suggesting a satisfactory model performance (Krause et al., 2005; Moriasi et al., 2007). The relative error is small (less than $4 \%$ ) in either the calibration or validation period. These indicate that the SWAT simulations can capture the temporal variations of streamflow reasonably well in the study area.

Figure 4 shows the SWAT-simulated annual natural streamflow at the Huayuankou station from 1960 to 2011. The mean annual natural streamflow is the largest in the base-

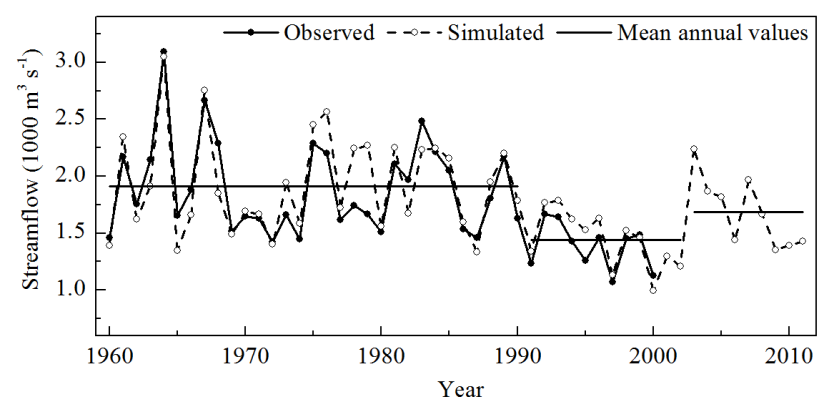

Fig. 4. SWAT-simulated annual natural streamflow at the Huayuankou station from 1960 to 2011 . The horizontal lines show the SWAT-simulated mean annual streamflow in the baseline (19601990), low-flow (1991-2002), and recent (2003-2011) periods.

line period and smallest in the low-flow period. In the recent period when precipitation slightly rebounded (Table 1), the natural streamflow substantially recovered (Fig. 4) compared with that in the low-flow period. The recent recovery of the natural streamflow enabled a greater amount of the available water resources for reservoir regulations and might contribute to the disappearance of the Yellow River zero-flow phenomenon after 2002.

Table 3 shows the mean annual streamflows estimated from the SWAT model and derived from the runoff elasticities in the baseline, low-flow, and recent periods. The mean annual streamflow derived from the runoff elasticities method was identical to the observed naturalized flow in the baseline period because the runoff elasticities were calculated using the data in that period. The mean annual streamflows derived from the runoff elasticities and estimated from the SWAT model match well with the observed naturalized streamflow in the low-flow period, with about $4 \%$ relative errors (Table 3). The observed naturalized streamflow in the low-flow period was $27 \%$ below the streamflow in the baseline period. Both the SWAT model simulation and runoff elasticities estimates captured the low flow, showing a $26 \%$ and $24 \%$ reduction in natural streamflow, respectively. In the recent period, the SWAT model showed a $12 \%$ reduction and the runoff elasticities method estimated a $14 \%$ reduction from the natural streamflow in the baseline period. The natural streamflow in the recent period was lower than that in the baseline period but higher than that in the low-flow period. Both the SWAT simulations and runoff elasticity estimates show that about half the reduction amount in the lowflow period has recovered in the recent period. The amount of natural streamflow recovery is about $13 \%$ of the mean annual steamflow in the baseline period (Table 3), which may have helped to replenish the drying river in the recent period.

Table 4 shows the runoff elasticities and the changes in climatic variables in the low-flow (1991-2002) and recent (2003-2011) periods compared to the baseline period (19601990), and the contributions of climatic variable changes to 
Table 1. Mean annual climatic variables and potential evaporation of the study area in the baseline (1960-1990), low-flow (1991-2002), and recent (2003-2011) periods.

\begin{tabular}{lrrrrrr}
\hline & $P(\mathrm{~mm})$ & $R_{\mathrm{n}}\left(\mathrm{MJ} \mathrm{m}^{-2} \mathrm{a}^{-1}\right)$ & $T\left({ }^{\circ} \mathrm{C}\right)$ & $U_{2}\left(\mathrm{~m} \mathrm{~s}^{-1}\right)$ & $\mathrm{RH}(\%)$ & $E_{0}(\mathrm{~mm})$ \\
\hline Baseline & 449 & 2599 & 7.48 & 1.735 & 58.67 & 1010 \\
Low flow & 402 & 2543 & 8.24 & 1.539 & 57.37 & 1002 \\
Recent & 413 & 2353 & 8.2 & 1.421 & 53.31 & 956 \\
Low-flow change relative to baseline & $-10.5 \%$ & $-2.2 \%$ & $0.76^{\circ} \mathrm{C}$ & $-11.3 \%$ & $-2.2 \%$ & $-0.8 \%$ \\
Recent change relative to baseline & $-8.1 \%$ & $-9.5 \%$ & $0.71^{\circ} \mathrm{C}$ & $-18.1 \%$ & $-9.1 \%$ & $-5.3 \%$ \\
\hline
\end{tabular}

Table 2. Performance of the SWAT model in the calibration (19601979) and validation (1980-2000) periods.

\begin{tabular}{lrr}
\hline & $E_{\mathrm{NS}}$ & $E_{\mathrm{r}}$ \\
\hline Calibration & 0.53 & $-1.0 \%$ \\
Validation & 0.68 & $-3.5 \%$ \\
\hline
\end{tabular}

runoff change. The runoff elasticity to precipitation $\left(\varepsilon_{\mathrm{p}}\right)$ is 2.6 , indicating that a $10 \%$ change in mean annual precipitation results in a $26 \%$ change in mean annual runoff (Table 4 ). The precipitation in the low-flow period was $10.5 \%$ below that in the baseline period and led to a $27.3 \%$ reduction in runoff. The runoff reduction caused by precipitation change was close to the decrease in the observed naturalized streamflow (27\% baseline runoff) in the low-flow period (Table 3 ). In the low-flow period, the total contribution from the other climatic variables (i.e., $R_{\mathrm{n}}$, wind speed, temperature, and relative humidity) to runoff change was relatively small (3.2\% baseline runoff). In the recent period, the precipitation was $8.1 \%$ below the baseline, which would lead to a $21 \%$ reduction in runoff. However, the reduction in natural streamflow was about $13 \%$ baseline runoff (Table 3 ). This suggests that the other climatic variables may have also affected runoff in the recent period. The increase in temperature $\left(0.71^{\circ} \mathrm{C}\right)$ had relatively small effects on runoff change, responsible for a reduction of only $3.3 \%$ baseline runoff. The decrease in relative humidity $(-9.1 \%)$ was responsible for a decrease of $7.1 \%$ baseline runoff. Contrastively, the decrease in $R_{\mathrm{n}}$ $(-9.5 \%)$ and wind speed $(-18.1 \%)$ contributed an increase of $7.2 \%$ and $10.7 \%$ baseline runoff, respectively. The contributions of $R_{\mathrm{n}}$ and wind speed offset the runoff reduction caused by temperature increase (3.3\% baseline runoff) and relative humidity decrease ( $7.1 \%$ baseline runoff) in the recent period, resulting in a total contribution of $7.5 \%$ of baseline runoff increase from the other climatic variables. The contribution from the other climatic variables formed the major part of the natural streamflow recovery amount that was about $13 \%$ of the mean annual steamflow in the baseline period (Table 3). The large positive contribution from the other climatic variables is consistent with the decrease in potential evaporation in the recent period (Table 1).
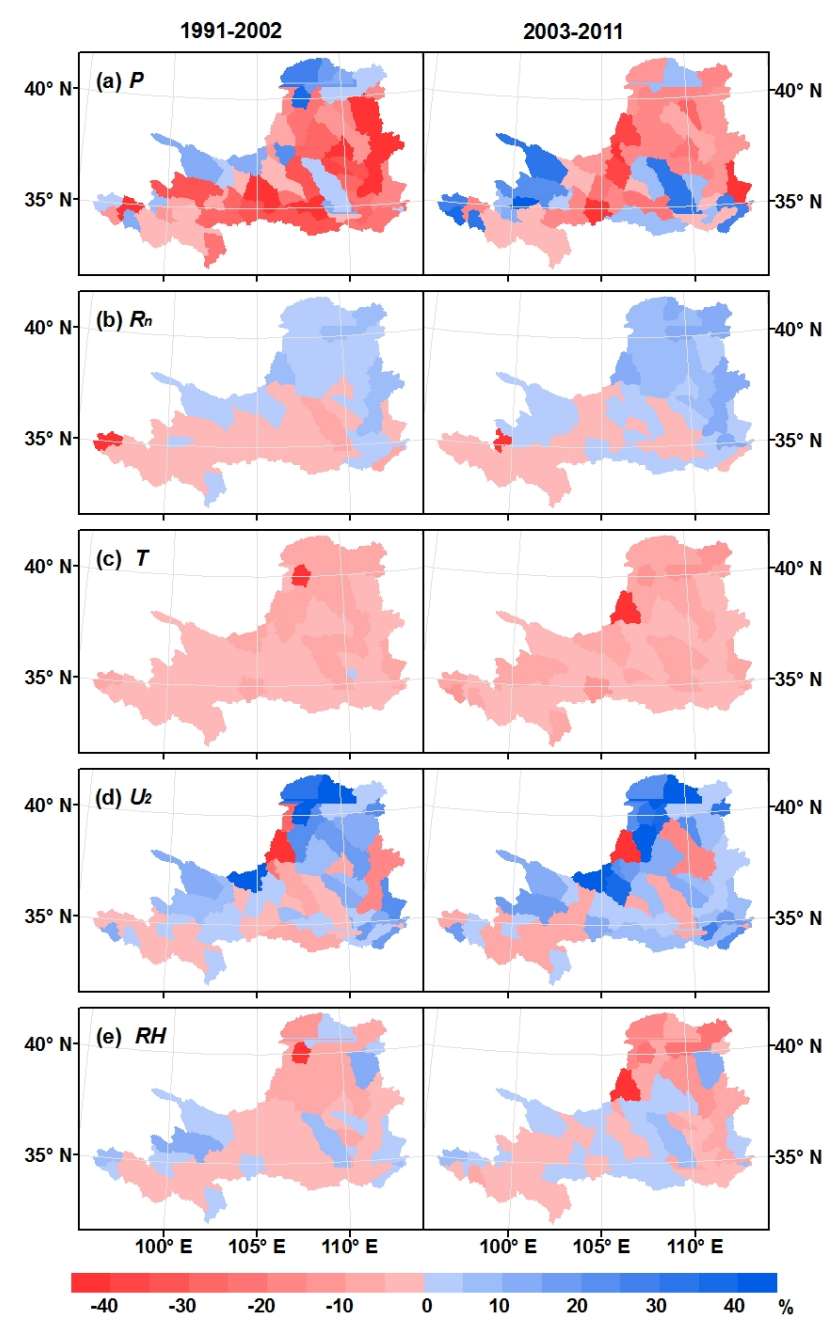

Fig. 5. The contributions of the changes in precipitation: (a) net radiation, (b) air temperature, (c) wind speed, (d) and relative humidity (e) to the runoff changes in the low-flow (left) and recent (right) periods at the sub-basins.

Figure 5 shows the contributions of the changes in climatic variables to the runoff changes at the sub-basins. Precipitation change is the major contributor to the runoff change in both the low-flow and recent periods. Precipitation was responsible for a more than $20 \%$ decrease in baseline runoff 
Table 3. Mean annual streamflows estimated from the SWAT model and derived from the runoff elasticities in the baseline (1960-1990), low-flow (1991-2002), and recent (2003-2011) periods.

\begin{tabular}{|c|c|c|c|}
\hline & Observed $\left(\mathrm{ms}^{-2}\right)$ & SWAT-simulated $\left(\mathrm{m} \mathrm{s}^{-2}\right)$ & Derived from elasticities $\left(\mathrm{m} \mathrm{s}^{-2}\right)$ \\
\hline Baseline & 1899 & 1934 & 1899 \\
\hline Low flow & $1382^{*}$ & 1441 & 1443 \\
\hline Recent & & 1710 & 1633 \\
\hline Low-flow change relative to baseline & $-27 \% *$ & $-26 \%$ & $-24 \%$ \\
\hline Recent change relative to baseline & & $-12 \%$ & $-14 \%$ \\
\hline
\end{tabular}

*The mean annual observed streamflow in the period of 1991-2000 was used because the naturalized streamflow data were unavailable after 2000 .

Table 4. Estimated runoff elasticities, climatic variable changes in the low-flow (1991-2002) and recent (2003-2011) periods to the baseline period (1960-1990), and contributions of climatic variable changes to runoff $(R)$ change.

\begin{tabular}{llrrrrr}
\hline Period & & $P$ & $R_{\mathrm{n}}$ & $T$ & $U_{2}$ & $\mathrm{RH}$ \\
\hline Baseline & Runoff elasticities $(\varepsilon)$ & 2.6 & -0.76 & -0.046 & -0.59 & 0.78 \\
Low flow & Relative change to baseline & $-10.5 \%$ & $-2.2 \%$ & $0.76^{\circ} \mathrm{C}$ & $-11.3 \%$ & $-2.2 \%$ \\
& Contribution to $R$ change $(\%)$ & -27.3 & 1.7 & -3.5 & 6.7 & -1.7 \\
\multirow{2}{*}{ Recent } & Relative change to baseline & $-8.1 \%$ & $-9.5 \%$ & $0.71^{\circ} \mathrm{C}$ & $-18.1 \%$ & $-9.1 \%$ \\
& Contribution to $R$ change $(\%)$ & -21 & 7.2 & -3.3 & 10.7 & -7.1 \\
\hline
\end{tabular}

at most sub-basins in the low-flow period. In the recent period, the runoff change caused by precipitation change was greater than $-20 \%$ at most sub-basins, and was positive in the western and northern areas of the upper reaches above the Lanzhou station and the southern areas of the middle and lower reaches (Fig. 1). The recent increase in precipitation in the western and northern portions of the source region has also been reported by a previous study (Zhou and Huang, 2012). The western and northern portions of the source region are in the arid area where the annual runoff and runoff coefficient are generally smaller than those in the humid area. Thus the big relative change in the precipitation and runoff at the specific area may have little impact on the total runoff generation of the basin (Zhou and Huang, 2012). The southern parts of the middle and lower reaches are in the semihumid area where the runoff change would have large effects on the total runoff generation in the Yellow River basin. The changes in runoff induced by the spatial patterns of the precipitation are different in the low-flow and recent periods, and this should be an important factor influencing the response of total runoff to precipitation in the basin.

The change in runoff caused by the change in net radiation is positive in the northeast but negative in the southwest basin in both the low-flow and recent periods (Fig. 5b). The area with positive contribution to the runoff change expanded in the recent period. In the low-flow period, the effect of the change in net radiation on runoff was much smaller than that of precipitation, as the runoff change induced by precipitation is large (over 20\%) in that period. However, the contribution of the net radiation change is comparable to (about one third of) the precipitation's in the recent period, not only because the effect of net radiation became larger, but also be- cause the effect of precipitation became smaller in the recent period. Temperature rise would result in a reduction in runoff generation across the basin (Fig. 5c). The effect of temperature rise on runoff is generally less than $5 \%$ of the baseline runoff at most sub-basins, and in both low-flow and recent periods equals approximately $15 \%$ of the precipitation's contribution. The runoff change caused by wind speed change is generally positive (Fig. 5d), likely due to the decline in wind speed during the study period (Fig. 2b). The effect of wind speed in the recent period is greater than that in the low-flow period and is comparable to (about half of) the precipitation's effect in the recent period. The runoff change caused by relative humidity change has a mixed pattern containing positive and negative ones that bears some resemblance to that of the precipitation change effect (Fig. 5e). The change in runoff induced by the change in relative humidity is generally between $-5 \%$ and $5 \%$ at most sub-basins and much less than precipitation's impact. The mixed pattern of the effect of relative humidity suggests that the runoff change at some parts may be cancelled out by the change at other parts. The spatial pattern of the relative humidity change should also be a factor influencing the response of total runoff to the change in the mean relative humidity.

\section{Conclusion}

The zero-flow phenomenon appeared frequently in the Yellow River in the 1990s. The drying up of the river was largely attributed to the runoff decrease in the upper and middle reaches (above Huayuankou station) and the increase in water withdrawals in the lower reaches (from Huayuankou station to the river mouth). In recent years, the zero-flow 
phenomenon has almost disappeared. We used a hydrological model together with runoff elasticity analyses to investigate the recent runoff change in the Yellow River basin above the Huayuankou station and the possible contributions of climatic factors to the runoff changes.

Our results show that there was little rebound of precipitation, but substantial recovery of runoff in the recent period (2003-2011) compared with the low-flow period (19912002). Precipitation in the recent period was slightly greater than precipitation in the low-flow period by $2 \%$ of the mean annual precipitation in the baseline period (1960-1990). However, the runoff in the recent period estimated by the model and runoff elasticity analyses was much larger than runoff in the low-flow period $(\sim 14 \%$ of the mean annual runoff in the baseline period). Although the runoff in the recent period was still $12 \%$ less than the baseline runoff, the runoff recovery may have contributed to the replenishment of the drying river.

The runoff elasticity analyses show that the decrease in runoff in the low-flow period was mainly caused by the decrease in precipitation, whereas decreasing $R_{\mathrm{n}}$ and wind speed were largely responsible for the recent runoff recovery. In the low-flow period, precipitation was responsible for a large runoff reduction (27.3\% baseline runoff), while the other climatic variables accounted for a small runoff increase ( $3.2 \%$ baseline runoff). In the recent period, precipitation accounted for a runoff reduction ( $21 \%$ baseline runoff) and the other climatic variables accounted for a runoff increase ( $7.5 \%$ baseline runoff). The runoff reductions seemed largely offset by the contributions from the decreasing net radiation and wind speed, which resulted in a runoff increase (7.2\% and $10.7 \%$ baseline runoff, respectively).

The runoff change caused by precipitation change was positive in the arid area of the source regions and the semihumid area in the middle and lower reaches in the recent period. The runoff changes caused by the changes in precipitation and relative humidity have a mixed pattern containing positive and negative ones, suggesting that their effects on runoff changes at some parts may be cancelled out at other parts of the basin. The spatial pattern of the climatic variation should also be a factor influencing the response of runoff to climatic variation. The reduction of runoff induced by precipitation change was offset up to half by the impacts of changes in net radiation and wind speed at most sub-basins in the recent period.

Acknowledgements. Funding for this research is provided by the National Basic Research Program of China (No. 2012CB955403), the National Natural Science Foundation of China (Nos. 41171031 and 51190092), and the Hundred Talents Program of the Chinese Academy of Sciences. We thank the editor and anonymous reviewer(s) for their constructive comments.

Edited by: E. Morin

\section{References}

Allen, R. G., Pereira, L. S., Raes, D., and Smith, M.: Crop Evapotranspiration: Guidelines for Computing Crop Water Requirements, FAO, Rome, 1998.

Angström, A.: Solar and terrestrial radiation. Quart. J. Roy. Meteor. Soc., 50, 121-126, 1924.

Arnold, J. G. and Fohrer, N.: SWAT 2000: current capabilities and research opportunities in applied watershed modeling, Hydrol. Process., 19, 563-572, 2005.

Arnold, J. G., Srinivasan, R., Muttiah, R., and Willams, J. R.: Large area hydrological modeling and assessment part I: model development, J. Am. Water Resour. As., 34, 73-89, 1998.

Budyko, M. I.: Climate and Life, Academic, New York, 1974.

Chiew, F. H. S.: Estimation of rainfall elasticity of streamflow in Australia, Hydrolog. Sci. J., 51, 613-625, 2006.

Cong, Z., Yang, D., Gao, B., Yang, H., and Hu, H.: Hydrological trend analysis in the Yellow River basin using a distributed hydrological model, Water Resour. Res., 45, W00A13, doi:10.1029/2008WR006852, 2009.

Cui, B., Yang, Q., Yang, Z., and Zhang K.: Evaluating the ecological performance of wetland restoration in the Yellow River Delta, China, Ecol. Eng., 35, 1090-1103, 2009.

Dong, L., Jiang, X., Wang, Y., and Li, H.: Methods for reconstruction of naturalized runoff in the Yellow River Basin, Yellow River, 23, 35-37, 2001.

Fu, G., Chen, S., Liu, C., and Shepard, D.: Hydro-Climatic trends of the Yellow River Basin for the last 50 years, Climatic Change, 65, 149-178, doi:10.1023/B:CLIM.0000037491.95395.bb, 2004.

Fu, G., Charles, S. P., and Chiew, F. H. S.: A two-parameter climate elasticity of streamflow index to assess climate change effects on annual streamflow, Water Resour. Res., 43, W11419, doi:10.1029/2007WR005890, 2007.

Fu, G., Yu, J., Zhang, Y., Hu, S., Ouyang, R., and Liu, W.: Temporal Variation of Wind Speed in China for 1961-2007, Theor. Appl. Climatol., 104, 313-324, 2011.

Hansen, J., Sato, M., Ruedy, R., Lo, K., Lea, D. W., and MedinaElizade, M.: Global temperature change, Proc. Natl. Acad. Sci. USA, 103, 14288-14293, 2006.

Hu, H., Liu, D., Tian, F., and Ni, G.: A method of ecological reservoir reoperation based-on ecological flow regime, Advances in Water Science, 19, 325-332, 2008 (in Chinese).

Jiang, Y., Luo, Y., Zhao, Z., and Tao, S.: Changes in Wind Speed over China During 1956-2004, Theor. Appl. Climatol., 99, 421430, 2010.

Krause, P., Boyle, D. P., and Bäse, F.: Comparison of different efficiency criteria for hydrological model assessment, Adv. Geosci., 5, 89-97, doi:10.5194/adgeo-5-89-2005, 2005.

Li, Z., Liu, W., Zhang, X., and Zheng, F.: Impacts of land use change and climate variability on hydrology in an agricultural catchment on the Loess Plateau of China, J. Hydrol., 377, 35-42, 2009.

Lin, C., Yang, K., Qin, J., and Fu, R.: Observed coherent trends of surface and upper-air wind speed over China since 1960, J. Climate, 26, 2891-2903, doi:110.1175/JCLI-D-12-00093.1, 2013.

Liu, C. and Zheng, H.: Changes in components of the hydrological cycle in the Yellow River basin during the second half of the 20th century, Hydrol. Process., 18, 2337-2345, doi:10.1002/hyp.5534, 2004. 
Liu, J., Liu, M., Zhuang, D., Zhang, Z., and Deng, X.: A study on the recent spatial pattern changes of land use in China, Sci. China Ser. D, 32, 1031-1040, 2002 (in Chinese).

Liu, L., Liu, Z., Ren, X., Fischer, T., and Xu, Y.: Hydrological impacts of climate change in the Yellow River Basin for the 21st century using hydrological model and statistical downscaling model, Quatern. Int., 244, 211-220, 2011.

Liu, Q. and Cui, B.: Impacts of climate change/variability on the streamflow in the Yellow River Basin, China, Ecol. Model., 222, 268-274, 2011.

Liu, Q. and McVicar, T. R.: Assessing climate change induced modification of Penman potential evaporation and runoff sensitivity in a large water-limited basin, J. Hydrol., 464-465, 352-362, 2012.

Liu, Q., Yang, Z., Cui, B., and Sun, T.: The temporal trends of reference evapotranspiration and its sensitivity to key meteorological variables in the Yellow River Basin, China, Hydrol. Process., 24, 2171-2181, 2010.

Ma, X., Zhang, M., Li, Y., Wang, S., Ma, Q., and Liu, W.: Decreasing potential evapotranspiration in the Huanghe River Watershed in climate warming during 1960-2010, J. Geogr. Sci., 22, $977-$ 988, 2012

McVicar, T. R., Roderick, M. L., Donohue, R. J., Li, L., Van Niel, T. G., Thomas, A., Grieser, J., Jhajharia, D., Himri, Y., Mahowald, N. M., Mescherskaya, A. V., Kruger, A. C., Rehman, S., and Dinpashoh, Y.: Global review and synthesis of trends in observed terrestrial near-surface wind speeds: implications for evaporation, J. Hydrol., 416-417, 182-205, 2012.

Moriasi, D. N., Arnold, J. G., Van Liew, M. W., Bingner, R. L., Harmel, R. D., and Veith, T. L.: Model evaluation guidelines for systematic quantification of accuracy in watershed simulations, American Society of Agricultural and Biological Engineers, 50, 885-890, 2007.

Nash, J. E., and Sutcliffe, J. V.: River flow forecasting through conceptual models: Part I. A discussion of principles, J. Hydrol., 10, 282-290, 1970.

Penman, H. L.: Natural evaporation from open water, bare soil and grass, Proc. R. Soc. London Ser.-A., 193, 120-145, 1948.

Reuter, H. I., Nelson, A., and Jarvis, A.: An evaluation of void filling interpolation methods for SRTM data, Int. J. Geogr. Inf. Sci., 21, 983-1008, 2007.

Roderick, M. L. and Farquhar, G. D.: A simple framework for relating variations in runoff to variations in climatic conditions and catchment properties, Water Resour. Res., 47, W00G07, doi:10.1029/2010WR009826, 2011.

Sankarasubramanian, A., Vogel, R. M., and Limbrunner, J. F.: Climate elasticity of streamflow in the United States, Water Resour. Res., 37, 1771-1781, doi:10.1029/2000WR900330, 2001.

Saxton, K. E. and Rawls, W. J.: Soil water characteristic estimates by texture and organic matter for hydrologic solutions, Soil Sci. Soc. Am. J., 70, 1569-1578, 2006.

Schaake, J. C.: From climate to flow, in: Waggoner, P. E. (Ed.), Climate Change and U.S. Water Resources, JohnWiley, New York, 177-206, 1990.

Song, Y., Liu, Y., and Ding, Y.: A study of surface humidity changes in China during the recent 50 years, Acta. Meteorol. Sin., 26, 541-553, 2012.
Tang, Q. and Lettenmaier, D. P.: 21st century runoff sensitivities of major global river basins, Geophys. Res. Lett., 39, L06403, doi:10.1029/2011GL050834, 2012.

Tang, Q., Oki, T., and Kanae, S.: A distributed biosphere hydrological model (DBHM) for large river basin, Ann. J. Hydraul. Eng. JSCE, 50, 37-42, 2006.

Tang, Q., Oki, T., Kanae, S., and Hu, H.: The influence of precipitation variability and partial irrigation within grid cells on a hydrological simulation, J. Hydrometeorol., 8, 499-512, 2007.

Tang, Q., Oki, T., Kanae, S., and Hu, H.: Hydrological cycles change in the Yellow River Basin during the last half of the 20th Century, J. Climate, 21, 1790-1806, doi:10.1175/2007JCLI1854.1, 2008a.

Tang, Q., Oki, T., Kanae, S. and Hu, H.: A spatial analysis of hydroclimatic and vegetation condition trends in the Yellow River basin, Hydrol. Process., 22, 451-458, doi:10.1002/hyp.6624, 2008b.

Tang, Q., Vivoni, E. R., Muñoz-Arriola, F., and Lettenmaier, D. P.: Predictability of evapotranspiration patterns using remotelysensed vegetation dynamics during the North American monsoon, J. Hydrometeorol., 13, 103-121, doi:10.1175/JHM-D-11032.1, 2012.

Tang, W.-J., Yang, K., Qin, J., Cheng, C. C. K., and He, J.: Solar radiation trend across China in recent decades: a revisit with quality-controlled data, Atmos. Chem. Phys., 11, 393-406, doi:10.5194/acp-11-393-2011, 2011.

Wang, H., Yang, Z., Saito, Y., Liu, J., and Sun, X.: Interannual and seasonal variation of the Huanghe (Yellow River) water discharge over the Past 50 years: Connections to impacts from Enso Events and Dams, Global Planet. Change, 50, 212-225, 2006.

Wang, W., Shao, Q., Peng, S., Xing, W., Yang, T., Luo, Y., Yong, B., and $\mathrm{Xu}, \mathrm{J} .:$ Reference evapotranspiration change and the causes across the Yellow River Basin during 1957-2008 and their spatial and seasonal differences, Water Resour. Res., 48, W05530, doi:10.1029/2011WR010724, 2012.

Xu, C., Gong, L., Jiang, T., Chen, D., and Singh, V. P.: Analysis of spatial distribution and temporal trend of reference evapotranspiration and pan evaporation in Changjiang (Yangtze River) catchment, J. Hydrol., 327, 81-93, 2006.

$\mathrm{Xu}, \mathrm{H}$., Taylor, R. G., and Xu, Y.: Quantifying uncertainty in the impacts of climate change on river discharge in sub-catchments of the Yangtze and Yellow River Basins, China, Hydrol. Earth Syst. Sci., 15, 333-344, doi:10.5194/hess-15-333-2011, 2011.

$\mathrm{Xu}$, J.: The water fluxes of the Yellow River to the sea in the past 50 years, in response to climate change and human activities, Environ. Manage., 35, 620-631, 2005.

$\mathrm{Xu}, \mathrm{Z}$., Zhao, F., and Li., J.: Response of streamflow to climate change in the headwater catchment of the Yellow River Basin, Quatern. Int., 208, 62-75, 2009.

Yang, D., Li, C., Hu, H., Lei, Z., Yang, S., Kusuda, T., Koike, T., and Musiake, K.: Analysis of water resources variability in the Yellow River of China during the last half century using historical data, Water Resour. Res., 40, W06502, doi:10.1029/2003WR002763, 2004.

Yang, H. and Yang, D.: Derivation of climate elasticity of runoff to assess the effects of climate change on annual runoff, Water Resour. Res., 47, W07526, doi:10.1029/2010WR009287, 2011.

Yang, T., Zhang, Q., Chen, Y., Tao, X., Xu, C., and Chen, X.: A spatial assessment of hydrologic alteration caused by dam con- 
struction in the middle and lower Yellow River, China, Hydrol. Process., 22, 3829-3843, doi:10.1002/hyp.6993, 2008.

Yang, Z., Zhou, Y., Wenninger, J., and Uhlenbrook, S.: The causes of flow regime shifts in the semi-arid Hailiutu River, Northwest China, Hydrol. Earth Syst. Sci., 16, 87-103, doi:10.5194/hess16-87-2012, 2012.

Yu, J., Fu, Y., Li, Y., Han, G., Wang, Y., Zhou, D., Sun, W., Gao, Y., and Meixner, F. X.: Effects of water discharge and sediment load on evolution of modern Yellow River Delta, China, over the period from 1976 to 2009, Biogeosciences, 8, 2427-2435, doi:10.5194/bg-8-2427-2011, 2011.

Zhang, Q., Xu,C., and Yang, T.: Variability of water resource in the Yellow River basin of past 50 years, China, Water Resour. Manag., 23, 1157-1170, 2009.
Zhang, X., Tang, Q., Zheng, J., and Ge, Q.: Warming/cooling effects of cropland greenness changes during 1982-2006 in the North China Plain, Environ. Res. Lett., 8, 024038, doi:10.1088/17489326/8/2/024038, 2012.

Zheng, H., Zhang, L., Zhu, R., Liu, C., Sato, Y., and Fukushima, Y.: Responses of streamflow to climate and land surface change in the headwaters of the Yellow River Basin, Water Resour. Res., 45, W00A19, doi:10.1029/2007WR006665, 2009.

Zhou, D. and Huang, R.: Response of water budget to recent climatic changes in the source region of the Yellow River, Chinese Sci. Bull., 57, 2155-2162, doi:10.1007/s11434-012-5041-2, 2012. 